\title{
Pablo Palant en la historia de la enseñanza dramatúrgica en Argentina
}

\author{
Ezequiel Lozano \\ IHAAL, FFyL, UBA - CONICET, Argentina \\ ezequiellozano@filo.uba.ar
}

Fecha de recepción: 24/02/2021. Fecha de aceptación: 20/03/2021.

\begin{abstract}
El artículo propone una lectura del "Seminario para autores", desarrollado por Pablo Palant en Argentores, como un hito destacado de la historia de la enseñanza de dramaturgia en Argentina. Se rescata su carácter pionero y se pretende argumentar que mediante una novedosa modalidad de taller dicho espacio de formación fue un sitio de relevancia en tanto condensador de los primeros saberes locales de la formación escritural para la escena, desde la perspectiva del quehacer teatral independiente.
\end{abstract}

PALABRAS CLAVE: PALANT, TALLER, DRAMATURGIA, TEATRO, AUTOR

\section{Pablo Palant in the History of the Teaching of Theater Writing in Argentina}

The article proposes a reading of the "Seminario para autores", developed by Pablo Palant in Argentores, as an outstanding milestone in the history of drama teaching in Argentina. Its pioneering character is rescued and it is intended to argue that through a new modality of workshop this training space was a site of relevance as a condenser of the first local knowledge of scriptural training for the scene, from the perspective of argentinian independent theatre.

KEYWORDS: PALANT, WORKSHOP, DRAMATURGY, THEATRE, AUTHOR

El presente trabajo intenta iluminar un momento particular de la historia de la enseñanza de la dramaturgia en Argentina: el Seminario para Autores, de Argentores, creado y sostenido - extensamente en el tiempo- por el dramaturgo Pablo Palant. Se trataba de un taller de formación pionero, que ha aparecido múltiples veces mencionado en testimonios, entrevistas, artículos periodísticos e historias del teatro nacional; un espacio educativo singular que se ubicó en un momento histórico de transición, por lo que consideramos que ha operado como una condensación de los primeros saberes locales de la formación escritural para la escena desde la perspectiva del quehacer teatral independiente. 
El seminario se creó en 1958 con modalidad de taller para la escritura teatral, en un contexto en el que este tipo de vínculo pedagógico no contaba con un historial local ni latinoamericano ni internacional. La modalidad tallerística era un descubrimiento en aquellos años ávidos por lo nuevo (Terán, 2006). Quizás el otro antecedente contemporáneo de un dramaturgo que ofreció un programa de estudio para la escritura teatral haya sido el de Osvaldo Dragún, aunque carecía de la sistematicidad que desarrolló el establecido en Argentores. Nos referimos a la experiencia del año 1961, cuando Dragún fue invitado a Cuba para desarrollar un seminario de dramaturgia de corta duración, y se ubicó, así, como referente latinoamericano en el tema, a pesar de que se trató de una experiencia acotada en el tiempo.

Ni siquiera los talleres literarios eran habituales, todavía. Liliana Villanueva (2020), estudiosa de la cuestión, ha señalado algunos antecedentes latinoamericanos de la formación escritural en el campo de la literatura, destacando como punto de referencia, junto con una variedad de cursos surgidos en Cuba, el primer taller de narrativa colombiano, inaugurado en 1962 en Cartagena de Indias. En el territorio de Argentina, resultaron significativos los talleres de Abelardo Castillo y Liliana Heker, que fueron pioneros y de largo aliento a través del tiempo; estos guardaban "enormes paralelismos y un origen común a partir de las revistas literarias de los sesenta y los setenta, las reuniones y discusiones en cafés" (Villanueva, 2020: 15). Liliana Heker, quien valora enormemente la importancia de las revistas literarias en su propia formación, describió que en los años sesenta, las y los jóvenes escritores "se reunían en grupos de diez o veinte o más personas alrededor de las mesas de los cafés porteños -en especial el Café de los Angelitos y el Café Tortoni [...]-" (Villanueva, 2020: 14). Por su parte, Abelardo Castillo se adjudicó haber inventado los talleres literarios en el año 1969.

Sin embargo, se conservan testimonios de una experiencia anterior, a mediados de la década del sesenta, a cargo de Rodolfo Carcavallo en el Instituto Argentino de Ciencias. Sucedía en una casona sobre la calle Viamonte, en el mismo espacio donde este entomólogo trabajaba como investigador científico especializado en el mal de Chagas. Allí, Carcavallo convocaba, por ser poeta y amante de la literatura, a los primeros talleres literarios del país. Liliana Heker describía que "había poesía, había de todo. Yo di también clases ahí. Era una sala chica en una casa con muchas habitaciones. La gente se inscribía e iba a todas las charlas que quería" (Villanueva, 2020: 47). Asimismo, Isidoro Blaisten, en su libro Anticonferencias (1983), recordaba que dio clases de "Técnica Literaria" en ese sitio, en 1965. Junto con ellos, Ernesto Sábato, Jorge Luis Borges, Leopoldo Marechal, Ulyses Petit de Murat, Conrado Nalé Roxlo, Bernardo Kordon, Agustín Cuzzani, Dalmiro Sáenz, Abelardo Arias, Abelardo Castillo, Marta Lynch, Humberto Constantini, Haroldo Conti y Carlos Mastronardi tuvieron a su cargo algunas de las charlas de formación que allí se desarrollaron. Es notoria, en esta enumeración de referentes de las letras, la presencia de dramaturgos cuya labor pedagógica todavía espera ser estudiada.

Dentro de este panorama, la novedad que aportó el seminario dictado en Argentores era la propuesta de una modalidad de taller, el cual se ofrecía de manera sistemática y periódica desde una institución vinculada a la labor autoral. No es casual que haya sido Pablo Tischkovsky Palant (1914) quien desarrolló esa tarea, ya que trazó en su biografía -de dramaturgo premiado, traductor de obras de teatro, guionista, pedagogo, ensayista y crítico- una semblanza del quehacer teatral independiente en Buenos Aires durante el segundo tercio del siglo XX. Estuvo a cargo del espacio en cuestión hasta su muerte, en 1975.

El faro difusor de la consolidación del teatro independiente argentino se ha ubicado en la campana tañida por Leónidas Barletta para convocar al público en la década del treinta. Pablo Palant escuchó literal y metafóricamente esa campana y convirtió 
el teatro en su vida: no es un dato menor que haya vivido frente a la sala del Teatro del Pueblo (en su etapa en la Av. Corrientes 1530). Comenzó a dar sus primeros pasos en las artes escénicas junto a Barletta y estableció un contacto pleno con la ebullición de la actividad de los inicios del teatro independiente. A la par, se formó como abogado. Más tarde, se incorporó al Grupo Boedo. En 1939, participó en la fundación del grupo La máscara; uno de los lemas de esta agrupación era una frase de Álvaro Yunque, "El teatro no es un templo, es un taller" (Ordaz, 1999:343), casi una profecía del futuro de Palant como pedagogo de dramaturgia. En La máscara, además de haber estrenado varios de sus textos, pudo aprender del contacto con el multifacético teatrista Bernardo Graiver y, principalmente, formarse en puesta en escena con Ricardo Passano, director que llevó a los escenarios muchos de los estrenos de la agrupación. De modo que perteneció, como su contemporáneo Osvaldo Dragún, a esa generación de dramaturgos íntimamente ligados al quehacer teatral. En efecto, Palant estaba tan impregnado del aire de su época que fue uno de los primeros teatristas que firmó un artículo que le dio nombre a aquel fenómeno argentino como "movimiento de teatros independientes", según lo analizó la investigadora María Fukelman (2017:313).

Sus últimas dos décadas de vida las dedicó al sostenimiento del espacio pedagógico en cuestión: el Seminario para Autores, de Argentores. Esta usina de formación escritural para autores y autoras nóveles siguió en funcionamiento luego de su muerte, portando su nombre como legado. Además, como estudió Dubatti (2020), Palant fue iniciador de una experiencia pedagógica con espectadoras y espectadores a fines de los años sesenta, inaugurando grupos de estudio privados, a la manera de las actuales "escuelas de espectadores".

¿Qué posición ocupaba Palant en el campo cultural antes del Seminario? Ya era un autor estrenado; había publicado sus obras: Jan, el antisemita (1940), La huida (1940), El amormuerto (1942), Los días del odio (1946) y La dicha impia (1956-1957). Asimismo, desarrolló otras actividades intelectuales e intervenciones en el campo cultural: a finales de la década del treinta, escribió para la revista Conducta. Al servicio del pueblo (segundo órgano oficial del Teatro del Pueblo), dirigida por Leónidas Barletta; a comienzos de la década del cuarenta, codirigió la revista TEATRO. Una publicación mensual de Editorial Occidente, junto con Enrique Schcolnik (allí Palant publicó, en el N.ro 7-8 de 1941, su texto Diez horas de vida, el cual se había estrenado en 1938); en 1945, fue codirector de la publicación cultural Trompo. Zumba la libertad en su segunda época.

Pocos años antes del comienzo del seminario, podemos destacar un hecho capital de su biografía. En 1954, la editorial Poseidón dio a conocer en Argentina la primera traducción rioplatense de Esperando a Godot, revisada por su autor, Samuel Beckett. Se trataba de la traducción de Pablo Palant. Sobre esta, ya señaló Osvaldo Pellettieri la importancia de "observar la sincronía con la situación europea de la obra: en 1952 la publicó en París Editions de Minuit y en 1953 la puso en escena Roger Blin" (2003: 320). Por su parte, Dubatti (2012: 122) detalló que no fue esta la versión que por primera vez subió a los escenarios argentinos (en 1956), sino la traducción del director de la puesta en escena, Jorge Petraglia.

Por aquellos años, todavía no circulaba esa categorización de "teatro del absurdo" (inventada por Martin Esslin), y textos como Esperando a Godot abrían polémicas de lectura bien interesantes por lo inasible del material dramatúrgico. En dicha edición, Palant sumó un prólogo, en el que expresaba su lectura del texto beckettiano. Si bien su perspectiva no fue la más lúcida ni la que se convirtió en hegemónica sobre esa textualidad, tuvo la virtud de la primicia en el reconocimiento de la importancia de aquella obra dentro del teatro del mundo. En ese prólogo, el dramaturgo afirmaba: "Beckett dice con responsable lucidez que hay que elegir entre la inmanencia y la trascendencia, pero claro que toma partido por la segunda" (Palant, 1954: 7), y 
agregaba: "Ya le incluirán en algún "ismo" los clasificadores que no piensan, pues carecen de amor. No importa; los ismos pasan junto con los clasificadores que no clasifican, pero las obras quedan" (9). Su mirada pudo contrastarse pronto, en una publicación de 1955, con la lectura que hizo el investigador Francisco Javier, quien alineó al autor con la floreciente neovanguardia francesa y lo incluyó dentro de la tradición irracionalista de Swift y Joyce, tal como explicó Pellettieri (2003: 320). Para este último, la lectura de Palant sobre Esperando a Godot estaba posicionada desde el "realismo testimonial" (321), que entendía ese texto como "un desarrollo dramático destinado a probar una tesis realista" (320).

En la reflexión de Palant sobre el texto de Beckett, se incorporaban menciones que daban cuenta de su biografía teatral; por ejemplo, concluía ese prólogo comentando:

Me río cuando pienso en la sorpresa que se llevarán con ella los ortodoxos y los ortodoxos de la heterodoxia, los realistas y demás “istas”. No, señores: ni Aristóteles, ni las treinta y seis situaciones, ni jueguitos blandi-poéticos para niños que no piensan, envueltos en muchas luces y mucha plástica. Nada más que un texto, sin intriga, sin pasiones diarias, sin sentimientos idealizados (...). Como diría Roberto Arlt, "iqué cross a la mandíbula!" (Palant, 1954: 9-10).

Aquí, la referencia final al escritor, con quien Barletta había trabajado de manera cercana en el Teatro del Pueblo, no resultaba nada casual.

Otro episodio que nos acerca a la mirada de Pablo Palant sobre el oficio dramatúrgico y sus procesos de enseñanza se desarrolló paralelamente a la etapa del primer año de vida del Seminario en Argentores. La Comisión de Cultura de la Federación Argentina de Teatros Independientes (FATI) convocó a una mesa redonda de autores en la que participaron, además de Palant, Virginia Carreño, Osvaldo Dragún, Julio Imbert, Bernardo Roitman y Enzo Aloisi. De aquel encuentro nos quedó una crónica, firmada por Pedro Espinosa, en la revista Teatro popular, donde se evocaba lo siguiente: "Retomó la palabra Palant para decir que denunciaba como delincuentes morales a los que presionan sobre los autores jóvenes de talento para que escriban influidos por preconceptos. Si a una rosa se le ponen tutores apenas nace, llegará a ser la rosa que deseaba que fuera el jardinero, pero no la rosa que debía ser, que es lo importante" (Espinosa, 1958: 12).

\section{El Seminario}

Son pocos los datos que se han encontrado sobre el desarrollo de aquella experiencia pedagógica. Nos ha resultado llamativa la carencia de materiales en los archivos que dieran cuenta de ese espacio como un laboratorio para el aprendizaje dramatúrgico o que describieran con mayor precisión sus características de funcionamiento. En las fuentes consultadas, se evidenció la primacía de una mirada afectuosa hacia Palant, aunque con un manto de incertidumbre sobre los contenidos allí estudiados. Por ejemplo, el dramaturgo Roberto Perinelli expresó sobre el Seminario: "No lo quiero calificar porque no fui, pero había voces contradictorias acerca de si era bueno o malo" (2016:53).

Por otro lado, habiéndose desarrollado dentro de una institución tan central en el campo cultural argentino: ¿Por qué Argentores no se ocupó de preservar la memoria de este núcleo pedagógico tan cercano, como imaginaríamos, a sus propios objetivos? Tal vez, un atisbo de respuesta sobre esta ausencia pueda inferirse de la memoria del organismo, el libro Argentores. Su historia. La casa de los autores zda época. Allí su autora, Rosa Angélica Fabbri, luego de fechar en 1957 el momento en el que Pablo Palant se 
asoció a Argentores, señalaba que el dramaturgo pasó a ser "miembro informante de la Comisión de Cultura" (37). Desde ese rol, Palant le detalló a la propia institución los pasos que debía seguir para dejar constituido un Seminario. Ya en 1958, dicha Comisión accionó en esa dirección porque entendió que la creación de este sería una contribución para "disipar esa alusión descomedida que corría en el ambiente de que Argentores no era más que un simple mostrador para cobrar derechos y recibir reclamos por infracciones a la Ley de Propiedad literaria" (Fabbri, 2012: 41). Se trató de un episodio curioso, quizás clave para entender el asunto que explica que, en su origen, el Seminario haya tenido pretensiones de ser un medio para prestigiar a la propia institución, que se apoyó para hacerlo en Palant, una figura ya reconocida en el medio teatral de ese momento. De modo que, más allá de la vocación y las buenas intenciones que pudiera haber tenido el dramaturgo, el Seminario ocupó, inicialmente por los menos, un rol lateral en el área de extensión de la entidad, y funcionaba como una propaganda positiva para contrarrestar las críticas que esta institución venía recibiendo. A pesar de esto, Pablo Palant construyó laboriosamente un espacio de taller único y significativo para la cultura teatral en Buenos Aires. Dada la falta de materiales sobre el seminario mismo, creemos que reponer algo de las ideas de Palant sobre el teatro en general y sobre el texto dramático en particular puede resultar auspicioso para entender su praxis pedagógica.

En el Archivo INET [folio N.ro 71-820], pudimos consultar un artículo periodístico -sin fecha ni datos del medio en el que se publicó-, donde su autora, Débora S. De Cendoya, a través de una crónica necrológica, precisó algunas características del espacio en sí: el Seminario de Autores se llevó adelante en la sala Gregorio de Lafèrrere, de la Sociedad General de Autores de la Argentina, a lo largo de casi veinte años, organizado en jornadas de cinco horas, los días sábados por la tarde (aunque algunas temporadas, también se desarrolló los días lunes). Asistían tanto jóvenes con cierta experiencia en la creación literaria -pero no dramatúrgica- como personas con alguna experiencia en escritura teatral -pero carentes de una guía en su desempeño autoral-. De Cendoya valoraba en su nota la alta receptividad de Palant para quien quisiera formar parte de aquel taller. Asimismo, señalaba que se incentivaba a asistir a funciones teatrales para luego intercambiar opiniones con sus directores, quienes concurrían a dialogar en el Seminario. También, se organizaban mesas redondas con representantes del quehacer teatral (por ejemplo, mencionaba a Guillermo Gentile, Ricardo Monti, Carlos Gandolfo, Alberto Ure, Carlos Traffic, Oscar Fessler). De Cendoya detallaba que "el clima del Seminario era el de una constante solidaridad de grupo preconizada por Pablo Palant con sencillez, sin pretensiones de ninguna índole dejándola surgir y expresarse" (s/p).

La autora de la necrológica valoraba, en la personalidad de Palant, su ingenio, su alegría y su "profundo respeto, su cuidadosa forma de aproximarse al trabajo de un alumno, con profunda sabiduría y manos de seda sin herir nunca" (De Cendoya, $\mathrm{s} / \mathrm{p}$ ). El análisis de los textos dramáticos se enfocaba en la forma, con hincapié en el tratamiento dado a las ideas y a los personajes. Ante el pedido del alumnado de fórmulas, Palant respondía categóricamente: "No existen reglas para escribir teatro; el teatro es una forma de contar la vida" $(\mathrm{s} / \mathrm{p})$.

A comienzos del Seminario, fueron premiados los textos La colmena, de Alma Bressan, y Amarillo, de Carlos Somigliana, con mención y edición de las obras. Se trataba de dos personas que no solo formaron parte como talleristas de aquel espacio coordinado por Palant, sino que, en el transcurso de los años siguientes, colaboraron en la tarea de coordinación. Por ejemplo, cuando Palant sugirió reflexionar sobre la puesta en escena de su propia obra El trompo, en el teatro ABC, el análisis fue conducido por Bressan y Somigliana. En particular, Alma Bressan fue una de las alumnas históricas y reemplazante de Palant en el Seminario. Era hermana del dramaturgo Sergio De 
Cecco, con quien desarrolló de manera paralela una carrera autoral, prolífica escritora de radioteatros en la década del cincuenta, admiradora y traductora de Ugo Betti. También trabajó exitosamente como guionista para televisión. Se mudó a Mendoza en la década del setenta (ciudad en la que estaba radicada su tía Clara Giol Bressan, también autora), donde organizó un Seminario de Autores en la Universidad Nacional de Cuyo, extendiendo lo aprendido en su oficio y en la dinámica del taller de Argentores.

Además de Alma Bressan y Carlos Somigliana, la lista de personas que asistieron al Seminario también incluyó los nombres de Carlos Bravi, Ricardo Talesnik, Carlos Ferrari, Julio Mauricio, Orlando Leo, Raúl Héctor Castagnino, Horacio Otegui, Bernardo Canal Feijoo y Manuel Abraham Lotersztein (quien también estudió dramaturgia en el Departamento de Teatro de la UBA). Si bien se ha señalado que Ricardo Monti fue parte del alumnado, su propio testimonio lo ha desmentido. En una entrevista publicada en la revista Florencio, cuando le consultaron si existían talleres de teatro en su juventud, Monti respondió:

Había un seminario en Argentores, que dirigía el querido Pablo Palant, y que no hice. Y no sé muy bien qué procedimientos utilizaba. En ese momento, el taller literario más conocido era el de Abelardo Castillo y había otros, pero tampoco estuve en ninguno de esos grupos. Formaba parte de un sector de jóvenes escritores que nos reuníamos en los cafés de Buenos Aires: La Paz, (...) y La Academia para leernos los trabajos, que no eran de teatro sino de narrativa y poesía. Yo fui el que empecé privadamente los talleres de dramaturgia. (Monti, 2010: 56-57).

La praxis pedagógica y escritural de Ricardo Monti logró conceptualizar un ingrediente fundamental que signó un cambio trascendental para la historia de la enseñanza de dramaturgia en América Latina. Mauricio Kartun se ocupó, luego, de desarrollar y difundir pedagógicamente la misma cuestión: la imagen como centro de la creación (concepto que fundamentó Monti, en 1979, en su artículo titulado "Las imágenes en la creación literaria"). Sobre este punto, nuestro proyecto de investigación ya se ha detenido en otras intervenciones (García, 2019; Saba, 2019), basta señalar que fueron ambos teatristas quienes introdujeron un cambio en la construcción de un campo de saberes específicos en Argentina. Si bien los dos dramaturgos tuvieron contacto con el teatro independiente, a diferencia de sus predecesores, dieron un salto desde aquella experiencia hacia la construcción de un campo de conocimiento autónomo para la escritura teatral. Ahora bien, justamente el Seminario de Palant fue la antesala inmediata de esa transformación, un paso previo que reunió en su desarrollo prácticas y concepciones sobre el quehacer dramatúrgico, hegemónicas durante el segundo tercio del siglo XX.

Dicha reunión de ideas y conceptos quedó plasmada en su libro El texto dramático, publicación del Centro Editor de América Latina que el dramaturgo concretó luego de una década de llevar adelante el Seminario; por lo que es altamente probable que haya sintetizado, allí, muchas de las ideas que venía compartiendo en aquel espacio tallerístico desde fines de la década del cincuenta. Fue en ese ensayo de 1968 donde Palant desarrolló conceptos nodales de su visión sobre la centralidad del texto dramático para el teatro. Escribió que una obra "supone siempre una finalidad y un camino para alcanzarla. El texto es el vehículo que recorre ese camino (...). Un texto es un cuerpo vivo, con alma (...) que se dirige rectamente a la comunidad, de la cual es confidente y depositario, testigo y exponente, capitán y esclavo" (Palant, 1968: 13). Esto, por medio de una particular concepción de lo artístico, consistía, para él, en "darle tal fuerza a la historia que su poder emocional sea capaz de sacudir vigorosamente la conciencia del espectador para sumergirlo en la historia que se le cuenta" (15). El propio Palant advertía que su filosofía era esencialista (al describir el concepto de personaje); sostenía que "un personaje es una singularidad que expresa una de las 
tantas y opuestas direcciones del ser del hombre" (18). Concebía el teatro como prisma antes que como espejo, ya que "el espejo sólo nos da la imagen de lo que parecemos, no de lo que somos. Y el teatro es lo que somos, no lo que parecemos" (28); "El autor, pues, inventa lo que ya existe, aunque no se conozca" (20).

Quisiéramos concluir con una cita de Palant que creemos describió con precisión el lugar del texto dramático en su pensamiento sobre las artes escénicas.

No, no hay teatro sin palabras. Cuando éstas son justas, nada las reemplaza. Cuando éstas pesan, cárguense a la cuenta del autor equivocado, nunca del teatro. Una obra servida por sus palabras precisas respira sin dificultades; es decir, se siente cómoda en cada situación, en cada momento culminante de su existencia, y esa respiración es la que determina el ritmo porque facilita el acoplamiento de los diversos momentos (...). Así, pues, la palabra precisa la situación, y ésta se articula en torno de ella a través de un desarrollo que entrega, cuando corresponde, las claves de la obra. Esa situación así insertada fija el ritmo que la obra necesita para transcurrir hacia el final, sin apremios y con buena respiración, y ese ritmo es el que decide el interés constante del espectador, imprescindible para que la obra se integre en él. (Palant, 1968:58).

Sobre el Seminario pudimos desgranar solo unos pocos datos más. En algún momento, Luis Ordaz tuvo a su cargo la cátedra Teatro Argentino. Luego de la muerte de Palant, el espacio siguió en actividad reformulándose, aunque siempre homenajeando a su impulsor. Ciertamente, el lugar central de este espacio de formación ocurrió en vida de Palant, es por ello importante reconstruir su historia.

Indudablemente, Pablo Palant ocupó un rol importante en la historia de la pedagogía teatral en Argentina al constituir un espacio innovador desde su modalidad tallerística que no solo les permitió a varias personas desarrollar su escritura dramatúrgica, sino que también les ofreció herramientas de análisis y estudio de las puestas en escena y textos teatrales contemporáneos. Desde una mirada esencialista, posicionada desde el realismo, aunque expectante de las innovaciones poéticas de aquel entonces, el Seminario condensó una serie de concepciones sobre lo teatral que circulaba en el movimiento teatral independiente argentino de mediados del siglo xx. Desde una pedagogía afectuosa, cercana y cordial, Palant estableció las bases de confianza para desarrollar una modalidad de taller que permitía la lectura grupal de materiales y su reelaboración. Este elemento perduraría en los talleres posteriores, como los de Monti y Kartun. Si bien no avanzó en concepciones técnicas como lo hicieron ellos, sí dejó una huella perdurable en el camino de la historia de la enseñanza dramatúrgica en Buenos Aires. 


\section{Bibliografía}

»Cabrera, H. (2004). o9 de noviembre. "Reflexiones sobre el poder". Página 12. Disponible en: https://www.pagina12.com.ar/diario/espectaculos/subnotas/6-14827-2004-11-09.html

»Dubatti, J. (2012). Cien años de teatro argentino, Buenos Aires: Biblos.

»Dubatti, J. (2020). “Hacia una Historia Comparada del espectador teatral”. En Bracciale Escalada, Milena y Ortiz Rodríguez, Mayra (compiladoras) De bambalinas a proscenio: perspectivas de análisis para el estudio de las artes escénicas (8-23), Mar del Plata: Universidad Nacional de Mar del Plata.

»Espinosa, P. (1958). “Debaten autores nacionales”, Teatro popular. Órgano de la Federación Argentina de Teatros Independientes - №3 [Dir.: Andrés Lizarraga] (p.12)

»Fabbri, R. A. (2012). Argentores. Su historia. La casa de los autores za época, Buenos Aires: Dunken.

» Fukelman, M. (2017). El concepto de "Teatro independiente" en Buenos Aires, del Teatro del Pueblo al presente teatral Estudio del período 1930-1946. [Tesis de doctorado]. Disponible en: http://repositorio.filo.uba.ar/handle/filodigital/4668

» García, E. (2019). "Pasado y presente de la enseñanza de la dramaturgia en la Argentina: Ricardo Monti”, en XXV Jornadas Nacionales de Teatro Comparado, Instituto de Artes del Espectáculo (UBA). [Ponencia inédita].

»Monti, R. (2010). dic. “Ricardo Monti. Una pasión argentina” Florencio, ํ24, p. 54-63.

» Ordaz, L. (1999). Historia del teatro argentino, Buenos. Aires: Instituto Nacional del Teatro.

»Palant, P. (1954). “Prólogo”. En Beckett, Samuel. Esperando a Godot (pp.7-10). Buenos Aires: Poseidon.

»Palant, P. (1968). El texto dramático, Buenos Aires: Centro Editor de América Latina.

»Pellettieri, O. (d.) (2003). Historia del teatro argentino en Buenos Aires: La segunda modernidad (1949 - 1976), Buenos Aires: Galerna.

»Perinelli, R. (2016). “Un autor de teatro que no lee obras está loco". Florencio №43 (pp.52-55).

"Saba, M. (2019). “Premisa o imagen: rupturas y continuidades en la historia del Curso de Dramaturgia de la EMAD”, en XX Jornadas de Investigación del Instituto de Historia del arte argentino y latinoamericano "Luis Ordaz" (UBA). [Ponencia inédita].

» s/f (1959, o4 de diciembre). "Orestes Caviglia espera la "marcha sobre el Cervantes", Platea.

" s/f (1999, 11 de diciembre). "Murió Alma Bressan, autora de teleteatros", La Nación. Disponible en: https://www.lanacion.com.ar/espectaculos/murio-alma-bressan-autora-de-teleteatros-nid164552

»Terán, O. (2006). De utopías, catástrofes y esperanzas. Un camino intelectual, Buenos Aires: Siglo XXI editores. 
»Villanueva, L. (2020). Maestros de la escritura. Ciudad Autónoma de Buenos Aires: EGodot Argentina.

"Zayas de Lima, P. (1991). Diccionario de autores teatrales argentinos 1950/1990, Buenos Aires: Galerna 